\title{
Identifying Pollen Incompatibility Groups in California Almond Cultivars
}

\author{
D.E. Kester, T.M. Gradziel, and W.C. Micke \\ Department of Pomology, University of California, Davis, 95616 \\ Additional index words. breeding, genetics, inbreeding, Prunus amygdalus, Prunus dulcis
}

\begin{abstract}
Six cross-incompatibility groups, which contain most of commercially important California almond cultivars [Prunus dulcis (Mill.) D.A. Webb, syn. Prunus amygdalus Batch], and their self-incompatibility (S) allele genotypes are identified. Incompatibility groups include 'Mission' $\left(S_{\mathrm{a}} S_{\mathrm{b}}\right)$, 'Nonpareil' $\left(\mathrm{S}_{\mathrm{c}} \mathrm{S}_{\mathrm{d}}\right)$, and the four groups resulting from the 'Mission' $x$ 'Nonpareil' cross: $\left(S_{\mathrm{a}} S_{\mathrm{c}}\right),\left(\mathrm{S}_{\mathrm{a}} \mathrm{S}_{\mathrm{d}}\right),\left(\mathrm{S}_{\mathrm{b}} \mathrm{S}_{\mathrm{c}}\right)$, and $\left(\mathrm{S}_{\mathrm{b}} \mathbf{S}_{\mathrm{d}}\right)$, as represented by 'Thompson', 'Carmel', 'Merced' and 'Monterey', respectively. All seedlings from the 'Mission' $x$ 'Nonpareil' cross were compatible with both parents, a result indicating that these two cultivars have no alleles in common. Crossing studies support a full-sib relationship for these progeny groups and the origin of both parents from common germplasm. Cultivars in these six groups account for $\approx 93 \%$ of present California production, a result demonstrating a limited genetic base for this vegetatively propagated tree crop.
\end{abstract}

About $65 \%$ of the world almond production is in California, with $>166,500$ ha in production in 1990 (California Agricultural Statistics Service, 1990). The interplanting of cross-compatible pollinizer cultivars in what previously were often single-cultivar orchards led to dramatic improvements in productivity and production consistency (Tufts, 1919; Tufts and Philp, 1922).

Self-incompatibility in almond, a diploid tree crop $(2 \mathrm{n}=16)$, seems to be of the monogenic, gametophytic type (Socias $i$ Company, 1991 ) as are other self-incompatible crops in the Rosaceae (Crane and Brown, 1937; Crowe, 1964). The self-incompatibility (S) locus controls self- and intra-specific cross-incompatibility (CI), and a series of many distinct alleles seems to exist (Socias i Company, 1991). Crossa-Raynaud and Grasselly (1985) have assigned the genotypes $\left(\mathrm{S}_{1} \mathrm{~S}_{2}\right),\left(\mathrm{S}_{3} \mathrm{~S}_{4}\right)$, and $\left(\mathrm{S}_{7} \mathrm{~S}_{8}\right)$ to 'Cristomorto', 'Ai', and 'Tardy Nonpareil', respectively.

Tufts and Philp (1922), in their analysis of 23 early almond cultivars, established two CI groups (CIGs): a) 'Nonpareil' and 'I.X.L.' and b) 'Mission' (also known as 'Texas Prolific'), the main pollinizer for 'Nonpareil' at that time, and 'Languedoc' (different from the French cultivar of the same name). 'Long I.X.L.' and 'Profuse' have been added to the 'Nonpareil' CIG and 'Ballico' has been added to the 'Mission' CIG (Kester, 1963). Other early cultivars proposed by Kester and Asay, (1975) to be cross-incompatible include 'Jordanolo' and 'Harpareil', produced from a 'Nonpareil' $\times$ 'Harriott' cross; 'Reams' and 'Jubilee'; 'Kutsch', 'Rivers Nonpareil', 'Sultana', and 'Bigelow'; and 'Smith X.L.' and 'Drake', although crossing data no longer are available. Of these cultivars, only 'Mission' and 'Nonpareil' remain extensively planted. Newer cultivars, selected for improved horticultural performance and pollinizer efficacy, are being planted increasingly. Most of these new cultivars seem to be chance seedlings from 'Nonpareil' $\times$ 'Mission' crosses (Hauagge et al., 1987). Four CIGs would be expected in the progeny of a 'Nonpareil' $\times$ 'Mission' cross if parents shared no common $\mathrm{S}$ alleles.

A detailed understanding of CI relationships would clarify the origin of these cultivars and the source of important genetic

Received for publication 26 Oct. 1992. Accepted for publication 10 Apr. 1993. The data used in this paper were obtained since about 1975. Many individuals participated in the study during this period whose assistance we gratefully acknowledge Richard Asay, Jim Doyle, Karen Pelletreau, Jim Yeager, Lonnie Hendricks, Clay Weeks, and William Beres. Support for this research was provided by the Almond Board of California. The cost of publishing this paper was defrayed in part by the payment of page charges. Under postal regulations, this paper therefore must be hereby marked advertisement solely to indicate this fact. disorders, including noninfectious bud failure (Kester and Jones, 1970) and graft incompatibility with 'Marianna 2624' plum rootstock (Kester and Asay, 1975j. Knowledge of the $S$ locus genotype would also allow the rapid establishment of cultivar pollination requirements and assessment of pollination efficiency for various genetic combinations, including the consequence of the pollinizer having an $S$ allele in common with the main cultivar. The purpose of this study was to identify the CIGs to which these new cultivars belong and to define their genetic relationships.

\section{Materials and Methods}

Plant material. More than 40 California almond cultivars were tested. Trees were at least 6 years old at the time of testing and were managed using standard methods at Univ. of California research orchards located at Davis or Winters and at regional cultivar trials in the Central Valley of California.

Pollination procedures. Pollen was collected from closed buds at the balloon and popcorn stages. Flowers were rubbed against screens to remove anthers, which were dried, sieved to remove debris, and stored at $\approx 5 \mathrm{C}$ in glass vials capped with nonabsorbent cotton (Kester and Asay, 1975).

Flower emasculation was used in the early tests but it entailed high labor requirements and was associated with pistil damage believed to reduce fruit set. Subsequent pollination tests involved nonemasculated flowers on limbs enclosed in mesh screen bags to prevent bee entry. No self-pollination would be expected due to the strong self-incompatibility in this crop. Flowers were hand-pollinated using a polished glass rod or similar device, which was sterilized with alcohol before and after pollination, after the petals had opened and expanded but before the stigma had turned brown. The number of flowers pollinated was recorded for each limb. Limbs bagged to exclude outside pollen were included as controls. Fruit set in adjacent open-pollinated limbs was also recorded as an indicator of natural set for that season.

CI determination. Seed set following controlled crosses was recorded as the ratio of developing nuts to the total number of flowers pollinated. Developing nuts were counted when the nonfertilized nuts had dropped and remaining nuts were $>1 \mathrm{~cm}$ long. This stage typically occurred 3 to 4 weeks after anthesis. A second count was usually made before nuts matured.

Between 400 and 1000 flowers were pollinated for each cultivar combination tested, Data from at least 2 years were pooled for final compatibility determination after analysis of variance tests had 
indicated no significant year effect. Combinations resulting in $\leq 5 \%$ seed set were considered incompatible. Combinations resulting in $>20 \%$ set were classified as cross-compatible. A few cultivar combinations showed pooled set levels between these limits but were not included in this analysis because the affected cultivars were not commercially important.

CIG determination. All cultivars demonstrating CI with a member of a putative CIG were tested further with other cultivars in that group. Compatibility between groups was established through crosses between one to three cultivars representative of each CIG (Table 1).

$\mathrm{S}$ genotype assignment for CIG-III. Twenty four seedling trees from the controlled 'Nonpareil' $\mathrm{x}$ 'Mission' cross were tested for seed set following separate pollination by 'Nonpareil', 'Mission', 'Thompson' (CIG-III), and 'Merced' (CIG-IV).

$\mathrm{S}$ genotype identification for $C I G-V$. Three seedlings resulting from the 'Nonpareil' $\times$ 'Thompson' cross and three from its reciprocal were tested for seed set following pollination by 'Nonpareil', 'Thompson' (CIG-III), 'Merced' (CIG-IV), and 'Carmel' (CIG-V).

$C I G-V I$ detection. Sixteen seedlings from the controlled 'Nonpareil' $\times$ 'Ne Plus Ultra' (CIG-IV) hybridization were tested for seed set following pollination by 'Nonpareil', 'Merced' (CIG-IV), and selection 1-98 (CIG-VI), one of the 16 seedlings produced by the 'Nonpareil' $x$ 'Ne Plus Ultra' cross.

$\mathrm{S}$ genotype identification for CIG-IV and CIG-VI. Cultivars representing the proposed CIGs I through VII (Table 1) and commercially important cultivars not identified with any CIG ('Monterey', 'Butte', 'Aldrich', 'Dottie Won', 'Fritz', 'Grace', 'Padre', 'Pearl', 'Ruby', 'Tokyo', and 'Wood Colony') were tested separately for seed set following pollination by selection 1-98 (CIG-VI) or 'Jeffries' as the pollen parent. 'Jeffries' is a bud mutation of 'Nonpareil', which seems to express only one $S$ allele $\left(S_{d^{-}}\right)$and is incompatible when selfed or crossed as the pollen parent with 'Nonpareil', 'Carmel', or 'Monterey', although all crosses to 'Jeffries' as seed parent are compatible (Kester et al., 1986).

Table 1. Cross-incompatibility groups (CIGs), as determined by controlled pollination studies among California almond cultivars.

\begin{tabular}{ll}
\hline \hline CIG & Cultivars \\
\hline I & Nonpareil, I.X.L., Long I.X.L., Profuse, Tardy Nonpareil \\
II & Mission, Ballico, Languedoc \\
III & Thompson, Robson, Harvey, Granada, Sauret no. 2, Mono, \\
& Wood Colony \\
IV & Merced, Ne Plus Ultra, Price Cluster, Norman, Ripon, Rosetta \\
V & Carmel, Carrion, Sauret no. 1, Livingston, Monarch \\
VI & Monterey, seedling 1-98 \\
VII & Sonora, Vesta, Solano, Kapareil \\
\hline
\end{tabular}

Table 2. Cross-compatibility response following controlled pollinations to progeny of a 'Nonpareil' $\times$ 'Mission' cross using pollen from 'Mission' $\left(S_{a} S_{b}\right)$, 'Nonpareil' $\left(S_{c} S_{d}\right)$, CIG-III, and CIG-IV.

\begin{tabular}{lccccc}
\hline \hline & \multicolumn{2}{c}{ Progeny (no.) } & & \\
\cline { 2 - 3 } Pollen parent & Compatible & Incompatible & & C h i - s q u a r e ${ }^{z} P$ \\
\hline Nonpareil & 24 & 0 & --- & --- \\
Mission & 24 & 0 & --- & --- \\
CIG-III & 18 & 6 & 0.05 & $>0.70$ \\
CIG-IV & 16 & 8 & 0.51 & $>0.40$
\end{tabular}

${ }^{\overline{ }}$ Expected ratio is 3 cross-compatible : 1 cross-incompatible for CIG-III and CIG-IV (with Yates correction).

\section{Results}

Seed set in bagged but nonpollinated control branches was usually $<1 \%$ and never $>5 \%$ for the cultivars tested. These selfing rates agree with previously reported almond selfing studies (Socias i Company, 1991). Seed set in cross-compatible combinations ranged from $10 \%$ to $50 \%$. Sets $<20 \%$ occurred in years of poor crop, usually due to rains during pollination. Such questionable compatibilities were retested in subsequent years, with $\geq 20 \%$ set used as an arbitrary indicator of cross-compatibility.

$C I G$ determination. Seven CIGs have been identified, including the 'Mission' $\left(S_{a} S_{b}\right)$ and 'Nonpareil' $\left(S_{c} S_{d}\right)$ groups and the four putative 'Mission' $\times$ 'Nonpareil' progeny groups CIG-III, CIG-IV, CIG-V, and CIG-VI (Table 1). Four $S$ genotypes $-S_{a} S_{c} S_{a} S_{d}, S_{b} S_{c}$, and $S_{b} S_{d}$-would be expected within progeny of a 'Mission' $\times$ 'Nonpareil', cross, with each CIG being equally probable in a nonselective environment. Isozyme data (Hauagge et al., 1987) and, where available, breeding records indicate that 'Sonora' and 'Solano' are not members of the 'Mission' $x$ 'Nonpareil' progeny group. Therefore, these cultivars were assigned to CIG-VII. Twenty-nine of the 41 cultivars tested have been placed in one of these seven CIGs, with the CI identity of the remaining 12 cultivars separate from these established groups.

S genotype assignment for CIG-III. The CI of CIG-III and CIG-IV with individuals from a 'Nonpareil' $\times$ 'Mission' progeny population demonstrate $S$ allele identity, thus, membership in one of the 'Mission' $\times$ 'Nonpareil' progeny CIGs (Table 2). None of the 24 progeny was cross-incompatible with either the 'Mission' or 'Nonpareil' parents, a result demonstrating that these parents have no $\mathrm{S}$ allele in common. While the data do not permit identification of specific genotypes, CIG-III arbitrarily can be assigned the genotype $S_{a} S_{c}$.

$\mathrm{S}$ genotype identification for $C I G-V$. The CIG-III $\left(\mathrm{S}_{\mathrm{a}} \mathrm{S}_{\mathrm{c}}\right)$ cultivars (seed parents) $\times$ 'Nonpareil' $\left(S_{c} S_{d}\right)$ crosses resulted in two groups of seedlings $\left(S_{a} S_{d}\right.$ and $\left.S_{c} S_{d}\right)$, while the reciprocal crosses resulted in $S_{a} S_{c}$ and $S_{a} S_{d}$ seedlings (Table 3 ). This difference occurred because the seed parent contributes both $S$ alleles to the progeny, while only the pollen allele not common to the seedparent alleles is transmitted. Six seedlings were assigned to CIGs based on fruit set following pollinations by 'Nonpareil' and testers of CIG-III, CIG-IV, and CIG-V. Individual progeny expressing the 'Nonpareil' genotype $\left(S_{c} S_{d}\right)$ were identified by the presence of CI with 'Nonpareil'. Similar CI with CIG-III cultivars identified the genotype as $S_{a} S_{c}$ for those progeny. The third genotype result-

Table 3. Cross-compatibility response following pollinations using pollen from 'Nonpareil', CIG-III, CIG-IV, and CIG-V to progeny resulting from the controlled reciprocal 'Nonpareil' $\left(S_{c} S_{d}\right) \times$ CIG-III $\left(S_{a} S_{c}\right)$ crosses. ${ }^{2}$

\begin{tabular}{|c|c|c|c|c|c|}
\hline \multirow[b]{2}{*}{ Seed Parent } & \multicolumn{4}{|c|}{ Pollen parent } & \multirow{2}{*}{$\begin{array}{c}\text { Seed parent } \\
\text { genotype }\end{array}$} \\
\hline & Nonpareil & CIG-III & CIG-IV & CIG-V & \\
\hline \multicolumn{6}{|l|}{$\overline{\text { CIG-III } \times}$} \\
\hline \multicolumn{6}{|l|}{ Nonpareil } \\
\hline S 2-55 & - & + & + & + & $S_{c} S_{d}$ \\
\hline S 2-32 & + & + & + & - & $S_{a} S_{d}$ \\
\hline S 2-71 & + & + & + & - & $S_{S}^{a} S_{d}$ \\
\hline \multicolumn{6}{|l|}{ Nonpareil $\mathrm{x}$} \\
\hline \multicolumn{6}{|l|}{ CIG-III } \\
\hline S 2-2 & + & - & + & + & $S_{a} S_{c}$ \\
\hline S 2-13 & + & + & + & - & $S_{a}^{a} S_{d}^{c}$ \\
\hline S 2-17 & + & + & + & - & $S_{a} S_{d}$ \\
\hline
\end{tabular}


ing from this cross would be $S_{a} S_{d}$. CI of CIG-V with these individuals thus identified the CIG-V genotype as $S_{a} S_{d}$ CIG-IV was fully compatible with all progeny, a result supporting a separate genotype for this group. Since CIG-IV has previously been shown to be a member of one of the 'Mission' $\times$ 'Nonpareil' progeny groups (Table 2), its genotype is either $S_{b} S_{c}$ or $S_{b} S_{d}$.

$C I G$-VI detection. The backcross of CIG-IV (either as $S_{b} S_{c}$ or $\left.S_{b} S_{d}\right)$ to 'Nonpareil' $\left(S_{c} S_{d}\right)$ as the seed parent resulted in only $S_{b}$ pollen being compatible, regardless of whether the remaining allele was $S_{c}$, or $S_{d}$. Progeny thus will segregate for the two remaining 'Mission' $\mathrm{x}$ 'Nonpareil' progeny genotypes: $S_{b} S_{c}$ and $S_{b} S_{d}$. Seven individuals belonging to CIG-IV were identified by their CI with established CIG-IV cultivars (Table 4), while nine individuals compatible with CIG-IV, including selection 1-98, belong in the remaining CIG-VI category.

$S$ genotype identification for CIG-IV and CIG-VI. Selection 1-98 was used as a representative of the fourth CIG (CIG-VI) for testing against a range of almond cultivars, including several new ones, whose CIGs have not been determined (Table 5). 'Jeffries', a bud-sport of 'Nonpareil' with an apparent CI genotype of $S_{d}-$ (Kester et al., 1986), was also crossed to these selected seed parents. One commercial cultivar-'Monterey'-was cross-incompatible with selection 1-98 and thus would have an identical $S$ genotype. 'Jeffries' pollen also proved cross-incompatible on 'Monterey' and cross-compatible on 'Merced' and 'Price Cluster', which are CIG-IV cultivars. The cross-compatibility of 'Jeffries' pollen on CIG-IV cultivars indicates the absence of an $S_{d}$ allele in this group. As the two possible CIGs were $S_{b} S_{c}$ and $S_{b} S_{d}$, the genotype $S_{b} S_{c}$ is assigned to CIG-IV. Similarly, the CI of 'Jeffries' pollen on 'Monterey' supports an S genotype of $S_{b} S_{d}$ for this only known member of CIG-VI. Incompatible responses to 'Jeffries' pollen on 'Nonpareil', 'Carmel', 'Sonora', and 'Butte' identify these cultivars as also possessing the 'Jeffries' $\left(S_{d}\right)$ allele. The remaining $\mathrm{S}$ allele for 'Sonora' and 'Butte' cannot be determined with present data nor can either allele for 'Fritz' and 'Padre'. The full cross-compatibility of these cultivars to members of all presently established CIGs indicates distinctness from the groups noted, however.

\section{Discussion}

Seven CIGs have been identified, including the previously described 'Mission' and 'Nonpareil' groups (Kester and Asay, 1975) and the four CIGs expected from their progeny. Data from our crossing studies have allowed the identification of specific $S$ genotypes for these groups, providing a precise definition of their genetic relationship (Table 6). All predicted 'Mission' $\times$ 'Nonpareil' CIGs were identified in seedling populations and commercial cultivars (which originated predominantly as seedling selections).

CIG-VI is represented by one cultivar-'Monterey'-while other groups contained at least five commercial cultivars. CIG-III and CIG-VI together account for $<4 \%$ of 1990 production. The total production of CIGs is determined more by specific cultivar rather than total number of cultivars in groups, however. Plantings of 'Mission', 'Nonpareil', 'Thompson', and 'Carmel' represent virtually all of the acreage of their respective groups, with remaining cultivars usually constituting $<1000$ ha each. The high acreage of CIG-IV results from comparable contributions $(\approx 10,000$ ha each) from three cultivars-'Merced', 'Ne Plus Ultra', and 'Price Cluster'.

The identification of 'Ne Plus Ultra' as being in the 'Mission' $\times$ 'Nonpareil' progeny groups presents a dilemma, as its introduction preceded that of 'Mission'. 'Ne Plus Ultra', 'Nonpareil', and
Table 4. Cross-compatibility response following pollination of progeny from the controlled 'Nonpareil' $\left(S_{c} S_{d}\right) \times$ CIG-IV $\left(S_{b} S_{t}\right)$ cross using pollen from 'Nonpareil', CIG-IV, and seedling 1-98.

\begin{tabular}{lccccc}
\hline & \multicolumn{2}{c}{ Progeny (no.) } & & \\
\cline { 2 - 3 } Pollen parent & Compatible & Incompatible & & C h i - s q u a r e ${ }^{2} P$ \\
\hline Nonpareil & 16 & 0 & -- & --- \\
CIG-IV & 9 & 7 & 0.06 & $>0.70$ \\
$1-98$ & 7 & 9 & 0.06 & $>0.70$ \\
\hline
\end{tabular}

${ }^{\overline{2}}$ Expected ratio is 1 cross-compatible: 1 cross-incompatible for CIG-IV and 1-98 pollinations, (with Yates correction).

Table 5. Cross-compatibility response for representatives of commercially important cross-incompatibility groups (CIGs) following pollinations with selection 1-98 $\left(S_{b} S_{2}\right)$ and 'Jeffries' $\left(S_{d}-\right)^{z}$

\begin{tabular}{|c|c|c|c|}
\hline \multirow[b]{2}{*}{ Seed parent } & \multicolumn{2}{|c|}{ Pollen parent } & \multirow{2}{*}{$\begin{array}{l}\text { Genotype of } \\
\text { seed parent }\end{array}$} \\
\hline & $1-98$ & Jeffries & \\
\hline Mission & + & + & $S_{a} S_{b}$ \\
\hline Nonpareil & + & - & $S_{c} S_{d}$ \\
\hline Thompson (CIG-III) & -+ & + & $S_{a} S_{c}$ \\
\hline Merced (CIG-IV) & + & + & $S_{b} S_{c}$ \\
\hline Price Cluster (CIG-IV) & + & + & $S_{b} S_{c}$ \\
\hline Carmel (CIG-V) & + & - & $S_{a} S_{d}$ \\
\hline Sonora (CIG-VII) & + & - & $S_{p} S_{d}$ \\
\hline Monterey & - & - & $S_{b} S_{d}$ \\
\hline Butte & + & - & $S_{p} S_{d}$ \\
\hline Aldrich & + & + & ID \\
\hline Dottie Won & + & + & ID \\
\hline Fritz & + & + & ID \\
\hline Grace & + & + & ID \\
\hline Padre & + & + & ID \\
\hline Pearl & + & + & ID \\
\hline Ruby & + & + & ID \\
\hline Tokyo & + & + & ID \\
\hline Wood Colony & + & + & ID \\
\hline
\end{tabular}

${ }^{\overline{ }}$ Cross-compatible, (+), cross-incompatible (-), and insufficient data (ID).

Table 6. Summary of cross-incompatibility group (CIG) responses, their S genotypes, and proportion of 1990 acreage in California.

\begin{tabular}{|c|c|c|c|}
\hline CIG & Genotype & Cultivars & $\operatorname{Acreage}^{z}(\%)$ \\
\hline$\overline{\mathrm{I}}$ & $S_{c} S_{d}$ & $\begin{array}{l}\text { Nonpareil }^{\mathrm{yx}}, \text { I.X.L.. }{ }^{\mathrm{x}} \text {, Long I.X.L., } \\
\text { Profuse, Tardy Nonpareil }^{\mathrm{yx}}\end{array}$ & 51.7 \\
\hline II & $S S_{h}$ & Mission, Languedoc, Ballico & 10.0 \\
\hline III & $S_{a}^{a} S_{c}^{b}$ & $\begin{array}{l}\text { Thompson }{ }^{y}, \text { Robson, Harvey } \\
\text { Mono } \\
\text { Wood Sauret no. } 2^{\mathrm{x}} \text {, Granada, } \\
\text { Wony }\end{array}$ & 2.8 \\
\hline IV & $S_{b} S_{c}$ & $\begin{array}{l}\text { Merced }^{y}, \text { Ne Plus Ultra, Ripon, } \\
\text { Norman }{ }^{y} \text {, Price Cluster }{ }^{y}, \text { Rosetta }\end{array}$ & 14.3 \\
\hline V & $S_{a} S_{d}$ & $\begin{array}{l}\text { Carmel }^{y}, \text { Carrion }^{y}, \text { Sauret no. } 1^{y} \text {, } \\
\text { Livingston }^{x}, \text { Monarch }^{x}\end{array}$ & 12.6 \\
\hline VI & $S_{h} S_{d}$ & Monterey $^{\mathrm{x}}$ & 0.9 \\
\hline VII & $S_{, j} S_{d}$ & Solano $^{\mathrm{x}}$, Sonora, Vesta, Kapareil ${ }^{\mathrm{x}}$ & $<0.1$ \\
\hline None & $\begin{array}{l}S, S_{d}^{d} \\
S, S_{i}\end{array}$ & $\begin{array}{l}\text { Butte }^{\mathrm{x}} \text {, Grace } \\
\text { Aldrich, Dottie Won }{ }^{\mathrm{x}} \text {, Fritz, Pearl }{ }^{\mathrm{x}} \text {, } \\
\text { Ruby, Padre, Tokyo }\end{array}$ & 1.1 \\
\hline
\end{tabular}

${ }^{2}$ California Agricultural Statistics Service, 1990.

'susceptible to noninfectious bud failure (Kester et al., 1985).

'Shows possible graft-incompatibility with 'Marianna 2624' plum rootstock (Asai and Micke, 1994). 
'I.X.L.' originated from a single seedling orchard planted by A.T. Hatch, Suisun, Calif., in 1879 (Wickson, 1910; Wood, 1925). The predominant cultivars in early California plantings apparently originated from seedling material of the Languedoc region of France. Two early California cultivars were known as 'Languedoc' (previously reported to be in the 'Mission' CIG) and 'Princess', and may have been related to the population used by Hatch. 'Nonpareil' rapidly became the main cultivar because of its good tree and nut qualities, with 'Ne Plus Ultra' planted extensively as its pollinizer (Kester et al., 1991). 'Mission', originally called 'Texas Prolific' and originating in Houston, is thought to be a seedling of the French cultivar Languedoc 302, also from the Languedoc region of France. 'Texas Prolific' was introduced in about 1900 in California (Wickson, 1910), where it was renamed 'Mission' and quickly became a major pollinizer for 'Nonpareil'.

The possibility that present accessions of 'Ne Plus Ultra' are not the original Hatch selection but come from a later 'Mission' $\times$ 'Nonpareil' cross is not supported by historical records and tree and nut morphology (Kester et al., 1991), isozyme inheritance patterns (Hauagge et al., 1987), and pollen ultrastructure analysis (Mulas et al., 1988). As the Hatch seedlings and the original 'Mission' seedling reportedly originated from limited material brought to the United States from the Languedoc region of France, the $S$ alleles of 'Ne Plus Ultra' could be identical by descent to the $S$ alleles of 'Nonpareil' and 'Mission'. A recent and common origin for 'Mission' and the Hatch seedlings 'Nonpareil', 'Ne Plus Ultra', and 'I. X. L.' would indicate an even narrower genetic base for the cultivars that dominate California production.

While it is plausible that some of the CIG-III cultivars originated from natural 'Ne Plus Ultra' $\times$ 'Mission' crosses, this event is improbable due to a poor bloom overlap between these cultivars. Considerable bloom overlap occurs, however, between 'Nonpareil' and 'Ne Plus Ultra', so 'Monterey', the sole cultivar identified in CIG-VI, may have resulted from this cross.

Kester and Jones (1970) proposed that the extensive use of 'Nonpareil' as a parent for cultivars from controlled crosses and for seedling selections from open-pollinations in 'Nonpareil' with 'Mission' plantings has contributed to the proliferation of genetic disorders of 'Nonpareil'. The reported distribution of noninfectious bud failure and, to a lesser extent, graft incompatibility with 'Marianna 2624' plum rootstock (Asai and Micke, 1994; Kester et al., 1985) supports this proposal, as their incidence is closely associated with CIGs in which 'Nonpareil' is a probable parent (Table 6). This association would also support the 'Mission' $\times$ 'Nonpareil' cross rather than the 'Mission $x$ 'Ne Plus Ultra' cross as the parents of 'Monterey', since 'Monterey' shows evidence of a 'Nonpareil' -type graft incompatibility with 'Marianna 2624' and 'Ne Plus Ultra' does not. 'Monterey', 'Monarch', 'Butte', and 'Pearl' showed such a rapid collapse on 'Marianna 2624' rootstock that other, possibly independent, causes are also possible. Noninfectious bud failure is not commonly found in the cultivars that lie outside the 'Nonpareil' progeny groups, though this may be due, in part, to their limited plantings. Cultivars in CIG-VII are the progeny of 'Nonpareil' $x$ 'Eureka', with subsequent backcrossing to 'Nonpareil' ( 'Kapareil') or sib-matings between $F_{1}$ hybrids ('Solano' $\times$ 'Sonora'). The expression of the $S_{d}$ allele in 'Butte' and 'Grace' suggests that 'Nonpareil' is one parent, with the other parent unknown but not being 'Mission' or 'Ne Plus Ultra'. The remaining unclassified cultivars could have the $S_{d}$ allele from a 'Nonpareil' cross to an almond other than 'Mission'. Isozyme inheritance data indicates 'Mission' as a probable parent of 'Fritz' (Hauagge et al., 1987), although the cross-compatibility of 'Fritz' with all cultivars in the 'Nonpareil' $\times$ Mission' progeny groups make 'Nonpareil' as the other parent improbable. 'Padre' reportedly resulted from a controlled cross of 'Mission' $\mathrm{x}$ 'Swanson', a seedling selection of unknown origin (Kester et al., 1991). Similarly, 'Carmel' has been reported to be a bud mutation of 'Nonpareil' (Brooks and Olmo, 1972). However, 'Carmel' s' $S_{a} S_{d}$ genotype indicates a 'Nonpareil' $\mathrm{x}$ 'Mission' seedling origin.

'Nonpareil' accounted for $\approx 52 \%$ of the California acreage in production in 1990. 'Mission' and the four progeny groups account for an additional $41 \%$. Thus, $\approx 93 \%$ of the California almond acreage is planted to cultivars that seem to be closely related. While the identified $S$ alleles seem to segregate randomly in seedling populations, the scarcity of the allelic combinations $S_{a} S_{c}$ and $S_{b} S_{d}$ in commercial production suggests a possible association with reduced horticultural value. Evidence for $S$ allele linkage with deleterious genes has been discussed previously by Socias i Company (1991 ) for a European almond population.

The identification of specific $S$ genotypes for these CIGs will allow a more accurate assessment of such genetic linkages and pollinizer efficacy and efficiency in various crossing combinations. The identification of these major CIGs will also greatly facilitate the CI characterization of new cultivars, since results from test crosses with selected representatives of established CIGs will provide the $\mathrm{CI}$ relationships for all members of the CIGs.

\section{Literature Cited}

Asai, W. and W. Micke. 1994. Evaluation and selection of current varieties. In: J. Coats (cd.). Almond orchard management. Univ. of California Press, Berkeley.

Brooks, R.M. and H.P. Olmo. 1972. Register of new fruit and nut varieties. 2nd ed. Univ. of California Press, Berkeley.

California Agricultural Statistics Service. 1990. California fruit and nut acreage, 1990. California Dept. of Food and Agr., Sacramento.

Crane, M.B. and A.G. Brown. 1937. Incompatibility and sterility in the sweet cherry (Prunus avium L.). J. Pomol. 15:86-116.

Crossa-Raynaud,P. and C. Grasselly. 1985. Existence de groupes d'intersterilite chez l'amandier. Options Mediterranean CIHEAM/IAMZ 85/I:43-45.

Crowe, L.K. 1964. The evolution of outbreeding in plants. I. The angiosperms. Heredity 19:435-457.

Hauagge, R., D.E. Kester, S. Arulsekar, D.E. Parfitt, and L. Liu. 1987. Isozyme variation among California almond cultivars: II. Cultivar characterization and origins. J. Amer. Soc. Hort. Sci. 112:693-698.

Kester, D.E. 1963. California almond varieties. Calif. Agr. Expt. Sta. Ext. Serv. Lflt. 152: 1-8.

Kester, D.E. and R. Asay. 1975. Almonds. In: J. Janick and J.N. Moore (eds.). Advances in fruit breeding. Purdue Univ. Press, West Lafayette. p. 387-419.

Kester, D.E. and R.W. Jones, 1970. Non-infectious bud-failure from breeding programs of almond (Prunus amygdalus Batsch.). J. Amer. Soc. Hort. Sci. 95:492-496

Kester, D. E., T.M. Gradziel, and C. Grasselly. 1991. Almonds (Prunus). In: J.N. Moore and J.R. Ballington, Jr. (eds.). Genetic resources of fruit and nut crops. p. 290:701-758.

Kester, D. E., W.C. Micke, D. Rough, D. Morrison, and R. Curtis. 1985. Almond variety update. Calif. Agr. Expt. Sta. Bul. 34: 1-7.

Kester, D. E., W.C. Micke, and M. Viveros. 1986. Discovery of a mutation for loss of a pollen incompatibility allele in 'Nonpareil' almond. HortScience 21:766. (Abstr.)

Mulas, M., G. D’Hallewin, and G. Nieddu. 1988. Pollen ultrastructure of twenty almond cultivars. Adv. Hort. Sci. 2:88-95.

Socias i Company, R. 1991. Breeding self-compatible almonds. Plant Breeding Rev. 9:3 13-338.

Tufts, W.P. 1919. Almond pollination. Calif. Agr. Bul. 306.

Tufts, W.P. and G.L. Philp. 1922. Almond pollination. Calif. Agr. Bul. 346. Wickson, E.J. 1910. The California fruits and how to grow them. 5th ed. Pacific Rural Press, San Francisco.

Wood, M.N. 1925. Almond varieties in the United States. U.S. Dept. of Agr. Tech. Bul. 1282: 1-142. 